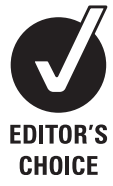

CHOICE
${ }^{1} 1$ st Department of Microbiology, Medical School, Aristotle University of Thessaloniki, Thessaloniki, Greece

${ }^{2}$ Mycology Reference Laboratory, Health Protection Agency, Bristol, UK ${ }^{3}$ Department of Medical Microbiology, University College London, Royal Free Hospital, London, UK

Correspondence to Dr Timoleon-Achilleas A Vyzantiadis, 1st Department of Microbiology, Medical School, Aristotle University of

Thessaloniki, Thessaloniki

54124, Greece;

avyz@med.auth.gr

Accepted 3 January 2012

Published Online First

3 February 2012

\title{
From the patient to the clinical mycology laboratory: how can we optimise microscopy and culture methods for mould identification?
}

\author{
Timoleon-Achilleas A Vyzantiadis, ${ }^{1}$ Elizabeth M Johnson, ${ }^{2}$ Christopher C Kibbler ${ }^{3}$
}

\begin{abstract}
The identification of fungi relies mainly on morphological criteria. However, there is a need for robust and definitive phenotypic identification procedures in order to evaluate continuously evolving molecular methods. For the future, there is an emerging consensus that a combined (phenotypic and molecular) approach is more powerful for fungal identification, especially for moulds. Most of the procedures used for phenotypic identification are based on experience rather than comparative studies of effectiveness or performance and there is a need for standardisation among mycology laboratories. This review summarises and evaluates the evidence for the major existing phenotypic identification procedures for the predominant causes of opportunistic mould infection. We have concentrated mainly on Aspergillus, Fusarium and mucoraceous mould species, as these are the most important clinically and the ones for which there are the most molecular taxonomic data.
\end{abstract}

\section{INTRODUCTION}

The incidence of fungal infection in the immunocompromised has continued to increase over the last two or three decades. Patients at high risk are those with leukaemia, tumours, diabetes and AIDS, those who have undergone major surgery, have extensive burns or wounds, or those who are under prolonged chemotherapy or radiotherapy. Transplant patients, premature newborns and the very elderly, particularly those with organ or circulation failure, are also at high risk.

Identification of fungi to the species or at least to the genus level is important in order to direct appropriate treatment. It is crucial to the development of knowledge and understanding of the pathogenesis and evolution of fungal diseases, for prediction of intrinsic resistance to antifungal agents and for the detection of clusters of nosocomial infection among hospitalised patients. In addition, it is important to recognise that many fungal isolates recovered from clinical samples do not represent significant disease. ${ }^{12}$ A careful evaluation of the clinical condition of the patient and a clear understanding of the likely clinical relevance of each isolate is important. ${ }^{3}$

The genera Aspergillus, Fusarium and Scedosporium of the division Ascomycota and members of the Mucoromycotina are among those moulds most commonly isolated from invasive infection. Accurate phenotypic identification has become more difficult in recent years as the phylogenetic taxonomy has revealed cryptic species within morphologically indistinguishable isolates. ${ }^{4}$ Most of the procedures used for phenotypic identification are based on experience rather than comparative studies of effectiveness or performance, and the majority of clinically important identifications of filamentous fungi are made using morphological criteria. ${ }^{6}$ Additionally, in order to evaluate the efficacy of new evolving molecular methods, there is a need for robust and certain phenotypic identification procedures.

The aim of this review is to summarise and evaluate the evidence for the major existing phenotypic identification procedures for the predominant causes of opportunistic mould infection. We have concentrated mainly on Aspergillus and Fusarium species and the mucoraceous moulds, as these are also the ones for which there are the most molecular taxonomic data.

The electronic journals database of the National Library of Health (UK), MEDLINE (journals and books), PubMed, EMBASE, the University College of London electronic journals and e-books, Web of Science, Biosis, Google books and Amazon books were searched. The output of this search was limited, and this review has also been written using supplementary evidence from other sources, including textbooks and manuals.

\section{PRE-EXAMINATION}

The clinical laboratory should provide guidance on specimen collection and transport, and use appropriate techniques and media in order to isolate the mould from the biological material. These methods should retain the viability of the fungus and obtain the maximum yield of organism. ${ }^{7}$

There are considerations that may influence the ways in which a specimen is processed. The anatomical site, the collection time, the transport media, any details concerning the underlying disease of the patient, information on travel to or residence in an area of endemic hazard group 3 fungi, occupation, any contact with animals, antifungal or antibacterial treatment, and cytotoxic or immunosuppressive drugs are the most relevant. ${ }^{7}$

\section{Specimen selection and collection}

Appropriate collection of the specimen is essential (table 1). There should be sufficient quantity for direct microscopy, culture or other procedures. Specimens should be received at the laboratory within 2-4 h, and if delayed, should be refrigerated in order to prevent overgrowth of commensal 
Table 1 Types of specimens for diagnosis of invasive mycoses ${ }^{7-9}$

\begin{tabular}{|c|c|}
\hline Pus (from abscesses or sinus tracts) & $\begin{array}{l}\text { Aseptically aspirated with a syringe and needle. If a swab must be used (not recommended), material should be } \\
\text { taken from as deep as possible }\end{array}$ \\
\hline Ulcerated lesions & Biopsied or excised or swabbed (less satisfactory) \\
\hline Mucous membranes and vaginal specimens & Scrapings for oral lesions or previously moistened (with sterile water or saline) swabs. Swabs for vaginal material \\
\hline Sputum & $\begin{array}{l}\text { Fresh, ideally collected in the early morning. Result of a deep cough (not saliva) or induced by aerosol, ideally after } \\
\text { rinsing the mouth and any dentures. } 5-10 \mathrm{ml} \text { in a sterile container }\end{array}$ \\
\hline $\begin{array}{l}\text { Other respiratory specimens (bronchoalveolar lavages } \\
\text { (BAL), bronchial brushings and washings tracheal } \\
\text { aspirates, bronchial secretions) }\end{array}$ & Aseptically collected and sent immediately to the laboratory \\
\hline Blood & $\begin{array}{l}\text { Venous or arterial blood (when venous blood cultures are unsuccessful). } 5-10 \mathrm{ml} \text { (accordingly to the instructions on } \\
\text { the bottle) collected into aerobic blood cultures bottles. } 2-3 \text { sets should be taken }\end{array}$ \\
\hline Bone marrow & $3-5 \mathrm{ml}$ in a sterile container with heparin 1:1000 or EDTA \\
\hline CSF & $3-5 \mathrm{ml}$ (less is acceptable for children and neonates) in a sterile container \\
\hline Eye & $\begin{array}{l}\text { Vitreous humour (ideally } 0.5 \mathrm{ml} \text {, less when undiluted). Corneal scrapings are inoculated directly onto appropriate } \\
\text { culture media. Tears and fluids can be collected with a loop or a sterile plastic pipette but will only be of value in } \\
\text { keratitis }\end{array}$ \\
\hline Ear & Scrapings of material from the ear canal. Swabs can be used \\
\hline $\begin{array}{l}\text { Body fluids (pleural, abdominal, synovial, peritoneal } \\
\text { dialysate) }\end{array}$ & $\begin{array}{l}\text { Aspirated or drained aseptically into sterile containers (with a sample for microscopy containing heparin 1: } 1000 \text { or } \\
\text { EDTA in the case of blood staining) or inoculated into aerobic blood culture bottles }\end{array}$ \\
\hline Urine & $\begin{array}{l}\text { Clean midstream sample (better early in the morning), catheter specimen or suprapubic (mostly in infants) aspirate. } \\
25-30 \mathrm{ml} \text { sent without delay to the laboratory }\end{array}$ \\
\hline Tissue & $\begin{array}{l}\text { Aseptically collected, from the centre and the edge of lesions. Sent to the laboratory fresh, in sterile saline (not } \\
\text { immersed in formalin) to prevent dessication }\end{array}$ \\
\hline
\end{tabular}

All samples should be collected and transported in sterile containers.

bacteria, $^{6}{ }^{10}$ although samples for dermatophyte investigation do not require this.

Collection of several specimens (from all affected sites) is important for the diagnosis of systemic mycoses. Blood culture should always be undertaken in a suspected systemic fungal infection. Aerobic blood culture conditions are employed. Examination of cerebrospinal fluid (CSF) is important in suspected fungal infections of the central nervous system (cryptococcal meningitis in particular). Vitreous samples of the eye can identify the cause of an endophthalmitis that could indicate a deeper infection, for example systemic Aspergillus or Candida infection, or a penetrating keratomycosis due to Candida, Aspergillus, Fusarium or other opportunistic moulds. Adequate corneal scrapings are important for the diagnosis of keratitis. Pleural, abdominal, synovial or continuous ambulatory peritoneal dialysis fluids can be aspirated or drained into sterile containers, to allow adequate microscopy, or inoculated into aerobic blood culture bottles for culture. 7 Interpretation of respiratory specimens should take account of the possible isolation of commensal flora or contaminating fungal spores. Sputum should be collected after deep expectoration, but bronchial specimens and bronchoalveolar lavages (BAL) are more reflective of a lung infection. It is recommended that at least three samples of sputum be submitted for microscopic examination and culture. ${ }^{8}$ In cases of invasive pulmonary aspergillosis, it has been found that the submission of three specimens was adequate to detect $91 \%$ of the cases. ${ }^{11}$ Underlying disease is critical in selecting patients in whom sputum cultures may be useful. Although cultures from respiratory secretions present a low sensitivity and uncertain specificity for aspergillosis, in patients with neutropenia or leukaemia the isolation of Aspergillus is highly predictive of invasive pulmonary aspergillosis. ${ }^{12-15}$

Midstream urine samples should be sent to the laboratory within no longer than $1-2 \mathrm{~h}$, as many potential contaminants grow well at room temperature. Nephrostomy or suprapubic aspirates are more reliable specimens for the upper urinary tract.

A tissue biopsy is a valuable diagnostic specimen (preferred to swab samples whenever possible), allowing immediate microscopic diagnosis of invasive fungal infection; subsequent culture may yield the pathogen for identification and susceptibility testing. 7

\section{EXAMINATION PHASE}

\section{Initial specimen processing and microscopy}

Samples from patients at risk of fungal infections with the UK category Hazard Group 3 organisms ${ }^{16}$ should be handled in Containment Level 3 conditions. This applies to all stages of processing where viable organisms may be present.

White blood cells in biological fluid, fungal hyphae or other fungal elements in conjunction with the suspected clinical diagnosis provide helpful information for the selection of the appropriate laboratory isolation and identification procedure, and the analysis of the results.

Whenever possible and with CSF, urine, BAL, continuous ambulatory peritoneal dialysis fluid, other body fluids or aspirates, a centrifugation step is necessary in order to concentrate the fungal elements; $1500 \mathrm{~g}$ for $5-10 \mathrm{~min}$ is adequate without destroying the fungal cells, although there is little evidence for the optimum force and duration. A measured aliquot of the sample is centrifuged, the supernatant is poured off and the sediment is resuspended in a measured small volume (100-250 $\mu \mathrm{l}) .^{7} 17$ A liquefaction step for specimens such as sputum is often necessary to prevent clumping and misssampling of the specimen. Liquefaction can be achieved with mucolytic agents such as $0.5 \%$ pancreatin, $0.5 \% \mathrm{~N}$-acetyl-Lcysteine or Sputolysin. A centrifugation step following this helps to concentrate the fungi. Tissues should be chopped carefully into smaller pieces, but not ground or homogenised, since this procedure is not suitable for the recovery of filamentous fungi, especially the mucoraceous moulds, due to their fragile nature.

\section{Rapid stains}

Lactophenol enables the natural colours of the fungal structure to be seen and at the same time it kills the fungus cells. When combined with cotton blue, it stains the fungal hyphae with a deep blue colour. This is particularly seen in the young growing parts with dense cytoplasmic contents (cotton blue is absorbed 
by the hyaline fungal structures). ${ }^{718}$ The pink stain lactofuchsin has been gaining in popularity with the move away from phenol-based preparations on health and safety grounds. The use of a $10-20 \% \mathrm{KOH}$ solution, with or without incubation of the wet preparation at $56^{\circ} \mathrm{C}$, is important for solid specimens or mucoid sputum samples to help soften and clear the host cells prior to staining. In a recent study on Aspergillus sinusitis, microscopy of sinus biopsy material cleared with $\mathrm{KOH}$ had a sensitivity of $78.4 \%$ in comparison with histological staining of the same samples. ${ }^{19}$

Optical brightener methods have been shown to be more sensitive than $\mathrm{KOH}$ wet mount and standard methylene blue staining in a number of specimen types. ${ }^{20}{ }^{21}$ Additionally, Calcofluor or Blankophor can be combined with $10-20 \% \mathrm{KOH}$, although it is better to pre-soften the tissue with $\mathrm{KOH}$ before addition of the fluorescent stain. While Calcofluor crystallises in an alkaline $\mathrm{pH}$, Blankophor does not and can be stored in a working solution for up to a year, if protected from light in the refrigerator. ${ }^{22} 23$ A study of respiratory samples (mostly BAL) from transplant recipients and neutropenic patients found a sensitivity of $88 \%$ and a specificity of $99 \%$ for the detection of Aspergillus-like elements by Blankophor in comparison with a $76 \%$ sensitivity for culture. ${ }^{24}$

Whichever stain is used (table 2), the sensitivity of direct examination depends on factors such as the quality and the type of the specimen, the quality of the microscope and the expertise of the microscopist. ${ }^{31}$

Microscopic criteria are critical for the objective diagnosis of invasive mould infections. The invasive septate moulds most commonly seen are hyaline Hyphomycetes, generally characterised by parallel cell walls, septation (cross wall formation in hyphae), lack of pigmentation and progressive dichotomous branching as in Aspergillus, Fusarium or Scedosporium species. At least 70 species from 20 genera have been implicated in hyalohyphomycoses. ${ }^{8}$

Aspergillus septate hyphae have a diameter of $3-6 \mu \mathrm{m}$ and each branch is approximately equal in width to the originating stem. Branching at $45^{\circ}$ angles is characteristic. In chronic lesions short distorted hyphae may be as wide as $12 \mu \mathrm{m}$ and antifungal treatment can also lead to aberrant forms in tissue. Occasionally conidial heads and/or conidia may be seen at an air/tissue interface, but usually members of the genus Aspergillus do not sporulate in vivo. Many other filamentous fungi (like Scedosporium, Fusarium and Scopulariopsis) present with a similar appearance in clinical samples, although with Scedosporium infections, annelloconidia may be seen in histological samples. ${ }^{32}$ Thus on direct microscopy one can usually only say that the infection is due to one of the agents of hyalohyphomycosis, although the balance of probability is that most infections will be due to Aspergillus.

Mucoraceous moulds have large $(3-25 \mu \mathrm{m}$ in diameter, average $12 \mu \mathrm{m}$ ) ribbon-like, multinucleated hyphal cells with non-parallel walls and infrequent septa. The branching is not dichotomous, is irregular and sometimes at right angles. Hyphae can appear distorted with swollen cells, or compressed, twisted and folded. ${ }^{2733} 34$ These differences can help to direct therapy before culture and identification results are available.

Another group of moulds causing tissue invasion with a distinctive appearance is the agents of phaeohyphomycosis, such as Alternaria and Curvularia. These fungi have melanin in their cell walls and appear as pigmented, septate hyphae. As many as 100 species from 60 genera have been implicated as agents of phaeohyphomycosis. ${ }^{35}$

\section{Histology stains}

Several histopathology staining (table 2) techniques can be used, especially with tissue specimens. ${ }^{6}{ }^{36}{ }^{37}$ Aspergillus spp. and the mucoraceous moulds stain fairly well with Papanicolaou or haematoxylin-eosin (H\&E), but Grocott-Gomori methenamine silver (GMS) stain is considered by many to be the best stain to reveal fungal hyphae. ${ }^{38}$ Another suitable stain is periodic acidSchiff (PAS) or the diastase modification (dPAS), which improves background staining by removing glycogen. However, some of the mucoraceous moulds stain less well with these stains.

Table 2 Rapid and histology stains available for fungal examination and identification ${ }^{7} 25-30$

\begin{tabular}{|c|c|c|}
\hline Stain & Use & Comments \\
\hline Calcofluor/Blankophor white & Detection of all fungi & $\begin{array}{l}\text { Rapid. Alone or in combination with } 10-20 \% \mathrm{KOH} \text {. Need for fluorescence microscope } \\
\text { at } 420 \mathrm{~nm}\end{array}$ \\
\hline Fontana-Masson stain & Histological stain for melanin & $\begin{array}{l}\text { Stains the cell wall of Cryptococcus neoformans. Especially useful for differentiation of } \\
\text { capsule-deficient } C \text { neoformans. Confirmation of melanin in lightly pigmented cells of } \\
\text { dematiaceous (dark coloured) fungi. Cell walls stain brown/black }\end{array}$ \\
\hline Giemsa & $\begin{array}{l}\text { Staining of bone marrow and peripheral } \\
\text { blood smears or sputum and BAL }\end{array}$ & Useful for Histoplasma and Pneumocystis species identification \\
\hline $\begin{array}{l}\text { Grocott-Gomori methenamine } \\
\text { silver stain (GMS) }\end{array}$ & Histological stain & $\begin{array}{l}\text { Provides optimal contrast for the detection of fungi in tissue. Specific for fungal cell walls. } \\
\text { Fungi stain black, dark brown or grey. Stains old and non-viable fungal elements most } \\
\text { effectively. Erythrocytes can mimic yeasts }\end{array}$ \\
\hline H\&E & General purpose histological stain & $\begin{array}{l}\text { Stains most fungi. Allows demonstration of host tissue reaction. Demonstrates natural } \\
\text { pigment in dematiaceous fungi. Not a specific fungal stain and fungal elements are easily } \\
\text { missed. Cartilage and calcium deposits dark blue, cytoplasm and other components } \\
\text { shades of red }\end{array}$ \\
\hline India ink & Negative staining. Especially useful in CSF & Rapid. Detection of Cryptococcus species (encapsulated) \\
\hline $\mathrm{KOH}$ & $\begin{array}{l}\text { Clearing of specimen to allow improved } \\
\text { visibility of fungal elements. Mostly with } \\
\text { solid specimens }\end{array}$ & $\begin{array}{l}\text { Rapid. With or without incubation at } 56^{\circ} \mathrm{C} \text {. May produce artefacts due to crystallisation } \\
\text { of the } \mathrm{KOH} \text { especially on drying }\end{array}$ \\
\hline Lactophenol & Lactophenol: preserves fungal structures and & Rapid. Clear and specific images of fungal elements. Mostly used at the identification steps \\
\hline Lactophenol-cotton blue & $\begin{array}{l}\text { kills the fungus. Cotton blue: stains the fungal } \\
\text { elements }\end{array}$ & \\
\hline Mayer's mucicarmine stain & Histological stain & $\begin{array}{l}\text { Specifically stains mucopolysaccharide capsular material of several fungi. May help in } \\
\text { confirmation of cryptococcal infection }\end{array}$ \\
\hline Papanicolaou stain & $\begin{array}{l}\text { Cytological stain mainly used to detect } \\
\text { malignant cells }\end{array}$ & Stains most fungal elements \\
\hline Periodic acid-Schiff stain & Histological stain & $\begin{array}{l}\text { Stains yeasts and hyphae. Possible artefacts with yeasts. Fungi appear red-purple. } \\
\text { Zygomycete hyphae may stain poorly }\end{array}$ \\
\hline
\end{tabular}


In cytology specimens, most fungi are identified and diagnosed by their morphological (hyphal or yeast structures, size, shape, budding, mode of branching) rather than staining characteristic. $^{38}$ This approach, combined with clinical information, helps in the selection of the stain that will display and enhance the morphological characteristics and in the differential diagnosis. Misclassification of moulds can occur at the microscopy stage when compared with the microbiological culture. The more significant characteristics that can be misinterpreted are those of septate versus non-septate hyphae (eg, Aspergillus species vs mucoraceous moulds) and the adequate identification of non-pigmented, branched, uniform, septate hyphae (as seen in several hyaline moulds, such as Aspergillus, Fusarium, Scedosporium and Penicillium species). ${ }^{39}$

According to international definitions, the main criterion for proven diagnosis of invasive fungal disease is based on histological examination (EORTC 2008). Although hyphal invasion of tissue specimens is considered diagnostic, ${ }^{40}$ in many instances the invasive infection is already in an advanced stage and, more importantly, obtaining tissue can be impractical in many cases owing to risks associated with the underlying disease. ${ }^{34} \mathrm{~A}$ positive culture is required to identify the infecting pathogen, although there have been promising reports of molecular identification from tissue samples. ${ }^{41-47}$

\section{Culture}

Media for the primary isolation of fungi should be for general purpose, non-selective and able to support the growth of most fungal pathogens. The growth of bacteria or saprophytic fungi can be reduced by the addition of inhibiting agents. Acidified media are generally inferior to antibiotic supplemented media. ${ }^{48} 49$ The antibiotics used are more effective when they are active against a broad range of bacteria, resistant to inactivation by medium components, stable during incubation of the medium and have no effect on the recovery of fungi ${ }^{50}$ The most widely used antibacterial agent is chloramphenicol. An advantage in using chloramphenicol is that it can be added to media before sterilisation. These media support the growth of moulds as well as yeasts. ${ }^{49}{ }^{51}$ Cycloheximide (actidione) is used for suppressing the fast growing saprophytic fungi, but it is not recommended for general use as it can inhibit certain pathogenic fungi, such as Aspergillus species and mucoraceous moulds.

Media routinely used for primary isolation are glucosepeptone agar (Sabouraud's agar, often with chloramphenicol) and malt extract agar (MEA). Brain heart infusion agar occasionally can be used as complementary and it is helpful for the yeast phase isolation of the dimorphic fungi. ${ }^{7}$

Petri dishes provide adequate conditions for the recovery of fungi, since a larger inoculum can be cultured and a greater and better aerated area is offered than in tube or bottle slants. Of course, all precautions should be taken in order to reduce the possibility of contamination ${ }^{7}$ and, as stated previously, samples and culture isolates from patients at risk of fungal infections with the UK category Hazard Group 3 organisms ${ }^{16}$ should be handled in Containment Level 3 conditions and inoculated in closed systems. The tendency for media in plates to dry out during prolonged incubation can be minimised by placing the plates into oxygen permeable cellophane bags. ${ }^{51}$

The performance of blood culture systems with respect to moulds has been poorly studied and most data refer to the isolation of yeasts. The repeated recovery of fungi from blood cultures is generally adequate evidence of infection, although such isolation happens rarely with Aspergillus. In contrast, Fusarium spp., are isolated from $60-70 \%$ of blood specimens from patients with disseminated fusariosis. Acremonium and Scedosporium species may also be isolated from blood during invasive disease. ${ }^{52}$ While a single blood culture positive for Aspergillus species most often represents a contaminant ${ }^{53}$ a high percentage of mould-positive blood cultures in high-risk patients represents contamination or indeterminate fungaemia. ${ }^{54} \mathrm{~A}$ number of blood cultures may be necessary for the recovery of the fungal pathogen.

Biphasic media (agar and broth phases) have a higher yield than broth systems (although this is based on yeast culture for the most part). ${ }^{37}$ Recovery rates may be improved by venting the culture bottles or by using lysis centrifugation. ${ }^{55}$ Biphasic bottles must be tilted daily to allow broth to flow over the agar surface. It is suggested that smears or stains are made frequently to detect fungal elements, and the broth should be inspected for the presence of suspended mycelial 'balls'. Cultures should be incubated at $30^{\circ} \mathrm{C}$ and maintained for 4 weeks. ${ }^{56}$ Mould recovery must be interpreted with caution with the lysis centrifugation method as it is more likely to be subject to contamination. ${ }^{57}$

The overall culture isolation rate of septate moulds such as Aspergillus and Fusarium from BAL or bronchial washing specimens is much higher than that from surgical and biopsy tissue specimens ( $8.1 \%$ vs $1.54 \%$ ). Cytologically positive BAL and bronchial washing specimens have a much higher culture yield. Fusarium seems to grow better and more frequently on culture than Aspergillus. The diagnosis of invasive aspergillosis is more dependent on tissue or fluid based microscopy. ${ }^{34}$ It has been reported that only $54 \%$ of patients with haematological malignancies had positive cultures for Aspergillus from lung tissue specimens with histological evidence of aspergillosis. ${ }^{58}$

\section{Growth temperature}

The optimum growth temperature for the main opportunistic pathogenic moulds is $30^{\circ} \mathrm{C}$. Additionally, an incubation temperature of $35-37^{\circ} \mathrm{C}$ should be used for the exclusion of those dimorphic fungi that grow as a mould at $30^{\circ} \mathrm{C}$ and as budding yeast at $35-37^{\circ} \mathrm{C} .{ }^{37}$ Aspergillus fumigatus can grow at much higher temperatures and $42^{\circ} \mathrm{C}$ can help to select for this pathogen. ${ }^{59}$ Maximum growth temperature is a feature used by many identification keys, especially with mucoraceous moulds. Another advantage of a higher temperature, that is, $35-37^{\circ} \mathrm{C}$, is that it may speed the growth of a number of fungi including Aspergillus species. ${ }^{60}{ }^{61}$ If a $30^{\circ} \mathrm{C}$ incubator is not available, cultures should be incubated at room temperature (approximately $25^{\circ} \mathrm{C}$ ). ${ }^{33}$ Plates should be kept for at least 2 weeks. It has been shown that most moulds are detected on culture by day $7(81 \%)$ and almost all by day $14(96 \%){ }^{62}$ Moulds recovered later were found to be only environmental contaminants of no clinical significance. All cultures should be examined at frequent intervals (at least three times weekly) and appropriate subcultures made. ${ }^{37}$

\section{Preliminary identification}

It is important to know if an isolate is a primary pathogen or an opportunistic fungus associated with infection. The growth of an opportunistic fungal pathogen should be carefully interpreted due to the possibility of contamination. For example, airborne Aspergillus spores may contaminate agar plates, and a very careful examination should be made. Predominant growth within the 'pool' or primary streaks and on several plates is strong evidence for the presence of the fungus within the sample. Recovery of a mould from specimens obtained from a sterile site such as blood, CSF or pleural fluid provides high suspicion of invasive fungal disease. However, recovery from 
specimens such as sputum, urine, pus or faeces is difficult to interpret and evidence of hyphae seen on direct microscopic examination can be valuable. The clinical history of the patient is crucial and nothing should be discarded as a contaminant without careful consideration. 763

The macroscopic examination of the colonies can reveal important characteristics concerning colour, texture, exudates, pigments, specific structures, growth rate and growth zones, and aerial (the hyphae projecting above the medium surface) and submerged or vegetative mycelium (the portion which penetrates the medium in order to secure the colony and absorb nutrients). The colour of the reverse of the colony must be recorded along with any pigment that diffuses into the medium. However, pigmentation can be a variable characteristic, even with the same strain. Pigmentation on the surface of the colony is usually caused by the spores and it is not evident until significant spore formation occurs. On the reverse, it is produced by soluble pigments and pigmentation of the vegetative hyphae, and may diffuse out into the agar. It is also helpful to observe the growth or not on medium containing cycloheximide. In all mould colonies there is a variety of morphological forms and textures. These will vary with the type of media, the incubation temperature and the age of the colony. Spores are produced from the aerial mycelium in characteristic ways. In moulds, hyphae are divided by cross walls, the septae (septate hyphae) into multicellular hyphae. Some species, such as the mucoraceous moulds, have few septae (nonseptate or coenocytic). All these characteristics can help in the identification of a large number of moulds, at least to the genus level. ${ }^{7} 1833$ Indeed, the molecular evidence currently emerging suggests that laboratories should probably be talking in terms of 'species complex' when only phenotypic examination has been undertaken.

\section{Needle or tease-mount preparations}

A needle mount allows good visualisation of these structures. With a pair of dissecting needles or stiff inoculating wires (perhaps bent to form a hook), a small portion of the colony should be placed on the slide, in a drop of lactophenol-cotton blue, lactofuchsin or $0.9 \% \mathrm{NaCl}$, covered with a coverslip and tapped sharply to spread the hyphae more regularly. Lactofuchsin is more viscous than lactophenol and may help to spread fungal hyphae more evenly in tease-mount preparations. The preparation should be observed with the lower $(\times 10)$ or higher power $(\times 40)$ objective for more detailed examination. In our experience and that of others, ${ }^{6}$ the oil immersion $(\times 100)$ objective can be helpful as it can reveal important features which are missed at lower magnifications. Unfortunately the needle mount method does not always render preservation of the original position and structure of the conidia, but it is rapid and often sufficient. ${ }^{73}$

\section{Tape mounts}

An alternative method, which is usually successful in retaining the original orientation of the characteristics, is the clear sticky tape mount. The sticky side of the tape is firmly pressed on to the surface of the fungal colony, then pulled away gently and placed with any elements stuck on it uppermost on a small drop of mounting fluid on a glass slide. A second drop of mounting fluid is placed on this and then covered with a coverslip. Gentle pressure on the coverslip will remove any small air bubbles. If no spores are found in the slide preparation, a new one can be made from an area nearer to the centre of the colony, where the mould is older and has had more time to sporulate. If there are too many spores and the spore-bearing structures cannot be discerned, it is better to try nearer the edge of the colony. ${ }^{33} 64$

\section{Slide culture}

As spore-bearing structures can be disrupted by the slide mount methods, the best method for preserving and observing them is the slide culture. A square block of a suitable nutrient agar, smaller than a coverslip, is placed on a sterile microscope slide supported on a bent glass rod in a Petri dish. The four sides of the block are inoculated with spores or mycelial fragments of the fungus, and it is covered with a sterile coverslip. Sterile distilled water is added to the dish, to protect the block from drying out, and the plate is incubated at $30^{\circ} \mathrm{C}$ with the lid on. Once there is adequate growth, the coverslip is removed and placed fungus side down on a drop of mounting fluid. If there is inadequate sporulation, a new sterile coverslip is placed on the agar block and the incubation is continued. At the end of the incubation period the agar block itself can also be removed and the adherent mycelium left on the slide can be observed in a drop of mounting fluid under a new sterile coverslip. An advantage is that the mounts can be sealed and preserved for future observation. ${ }^{64}$ Slide cultures, although not suitable for rapid identification, allow close observation of the features necessary for phenotypic identification to either species, species-complex or genera level depending on the organism in question. ${ }^{65}$ Another more rapid method is to push a sterile $18 \times 18 \mathrm{~mm}$ coverslip at a $45^{\circ}$ angle into a colony of the growing fungus. When the mould sporulates, the coverslip is carefully withdrawn and mounted in a drop of mounting fluid on a microscope slide. Another drop is placed on the top of the coverslip and a second larger coverslip, $22 \times 22 \mathrm{~mm}$, is placed on top. This too allows preservation of the morphology of the fungus in the orientation of the growing culture stuck on either side of the small coverslip. ${ }^{66}$

\section{Media and culture conditions to encourage sporulation}

Moulds grow best on rich media, but the overproduction of mycelium may result in loss of sporulation. 73764 This is often seen with Sabouraud's glucose agar medium. It becomes a more important issue when it is used for the preparation of slide cultures. ${ }^{65}$ A subculture to a less rich medium can encourage sporulation and may permit identification. Common media used for this purpose are cornmeal (CMA), oatmeal $(\mathrm{OA})$, potato dextrose (PDA) and Czapek-Dox agar, which is neutral and permits moderate to vigorous growth of aspergilli. ${ }^{18}$

Another approach for colonies that are growing less well on Sabouraud's agar is to subculture them to a nutritionally rich medium such as MEA, Borelli's lactritmel, which contains honey and milk, or V8 medium prepared from vegetable juices, resembling closer the natural habitat of the fungus.

For a small number of fungi, a problem may be the absence of the diurnal cycle to which they are naturally exposed. Incubation on a windowsill allows the cycle of light and dark to promote sporulation, and different types of sporulation may be seen among Aspergillus species under these conditions. ${ }^{67}$

\section{IDENTIFICATION}

The mycology laboratory relies on microscopic morphology for the identification of fungi. A good microscope and a good preparation are essential. Helpful is the eyepiece graticule which allows measurement of the size of fungal structures.

For the main three fungal groups of interest in this review, the incubation requirements for the subcultures described above are generally the same as for primary isolation. If the 
thermo-tolerance of the fungus is checked, then several temperatures such as $30^{\circ}, 35^{\circ}, 40^{\circ}, 45^{\circ}$ or $50^{\circ} \mathrm{C}$ can be used.

Identification keys are important for correct identification. Keys are algorithms that guide to the appropriate genus or species step by step, according to the observed morphological characteristics. Keys offer a degree of standardisation since they require use of specific media and conditions or they make use of specific characteristics. Many of the keys describe growth characteristics on Czapek-Dox agar, MEA or Sabouraud's glucose agar as the media of choice, and an incubation time of 7 days at $30^{\circ}$ and $35^{\circ} \mathrm{C}$ in aerobic conditions. ${ }^{6} 68$

\section{Aspergillus species}

Aspergillus colonies are usually fast growing and vary from white, yellow, yellow-brown, brown to black or with various shades of green. They mostly consist of a dense felt of erect conidiophores (differentiated hyphal structures bearing conidia) (figure 1). Under standardised conditions the colour or pigmentation, the rate of colony growth, the colony diameter and the surface texture are useful characteristics. Microscopically, the conidiophores terminate in a vesicle covered with a layer of flask-shaped phialides (uniseriate), which are cells with terminal

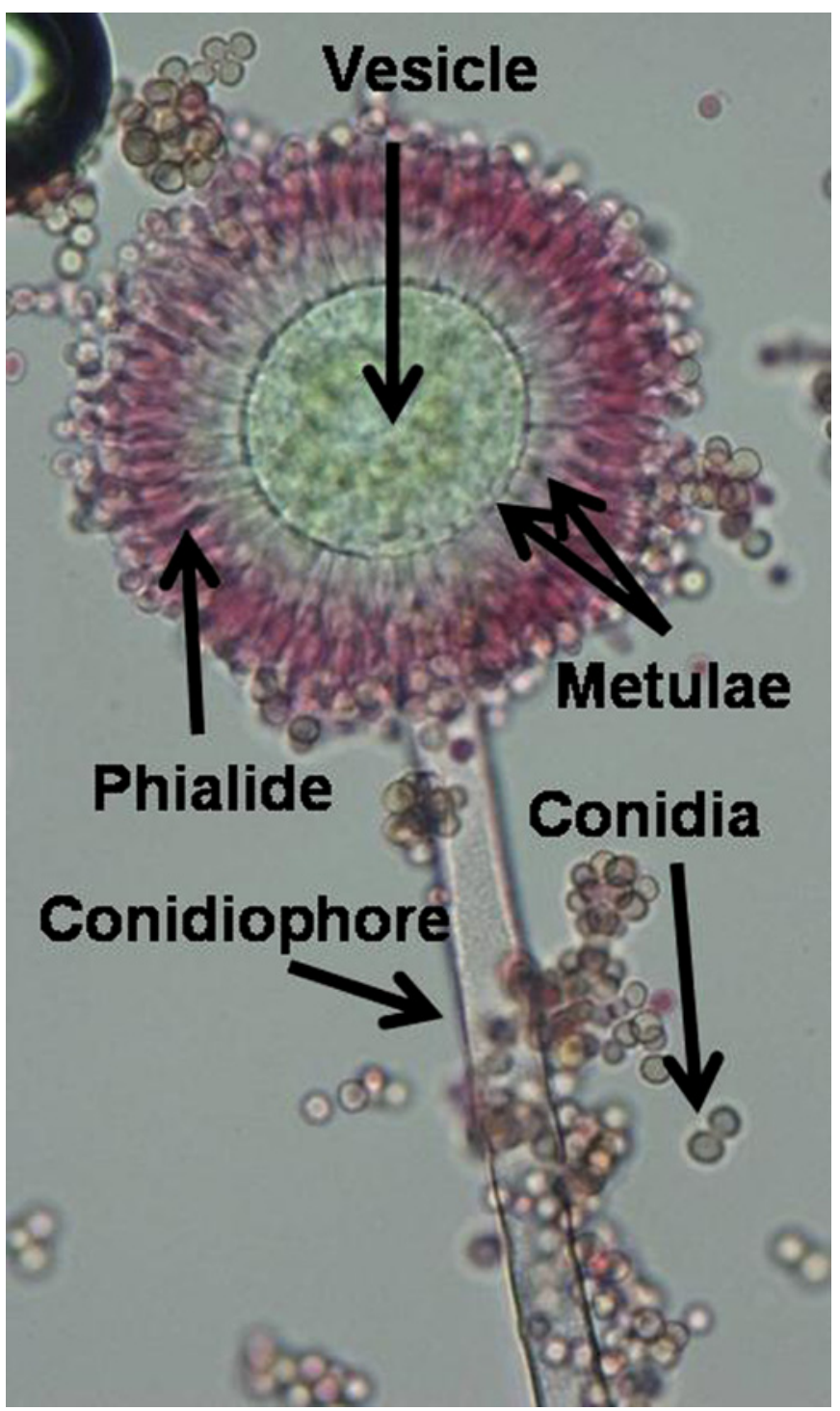

Figure 1 Aspergillus flavus sporing head. openings through which conidia are produced, or are covered with a layer of subtending cells (metulae), which bear small whorls of phialides (biseriate). Conidia are one-celled, smoothor rough-walled, hyaline or pigmented and they form long dry chains, which may be predominately radiate or columnar. Some species may produce Hülle cells, which are thick-walled cells that occur in association with ascomata. Ascomata or cleistothecia are enclosed fruiting bodies containing asci, which are sac like cells containing sexual spores known as ascospores. Ascomata and sclerotia (multicellular clumps which do not produce spores), are specific morphological structures. In general, Aspergillus key features are the septate hyaline hyphae and the distinctive conidial heads. ${ }^{6} 185669$ Molecular taxonomic studies have revealed that the section Fumigati, which includes the human pathogen $A$. fumigatus, comprises in excess of 29 species of Neosartorya and 14 Aspergillus species; and so with morphological identification it is best to refer to them as 'species complex' rather than a definitive species.

\section{Fusarium species}

Fusarium species produce fast growing colonies with pale or bright colours, which may have a cottony to woolly aerial mycelium or be quite mucoid. Colours vary from whitish to yellow, brownish, pink, orange, reddish or purple shades. Many species have colonies that are initially white and some remain so. Microscopically, phialides of varying widths and lengths arise from septate hyphae. Macroconidia and microconidia are produced from phialides (figure 2). Macroconidia $(3-8 \times 11-70 \mu \mathrm{m})$ are hyaline and have two to several transverse septae. They are fusiform (swollen near the middle and tapering towards the two ends) to sickle-shaped, mostly with an elongated apical cell and pedicellate basal cell (foot cell). Microconidia $(2-4 \times 4-8 \mu \mathrm{m})$ are single-celled, hyaline, pyriform (pear shaped), fusiform to ovoid, straight or curved and are formed singly, accumulate in small slimy heads or occasionally in chains. Fusarium microconidia resemble those of Acremonium. Chlamydoconidia may be as intercalary or terminal. However, there is marked variability between isolates in details such as conidia characteristics, colour of colonies or the production of macroconidia. Deviations from specified culture conditions can result in significant errors in morphological identification. ${ }^{70}$ One of the most common human pathogens in this genus, Fusarium solani, produces long, slender phialides and multi-septate, crescentshaped macroconidia. However, although this appearance is distinctive, the colony variation is wide and it is best to refer to F. solani species complex. Molecular studies have now shown that the morphogenetic types are comprised of at least 49 genetically distinct species, which cannot be distinguished by examination of their morphological features. ${ }^{4} 618335669$

\section{Mucoraceous moulds (zygomycetes)}

This group has undergone considerable taxonomic changes. Mucoraceous moulds produce fast growing colonies characterised by the production of primitive, mostly aseptate (coenocytic: multinucleate), hyaline, branched hyphae. Sexual reproduction in this group results in thick-walled structures called zygospores formed from the fusion of hyphal tips, either from compatible mating types (heterothallic) or from within a single strain (homothallic). The asexual spores, sporangiospores, may be contained within sporangia borne on simple or branched sporangiophores, or may be arranged around a swollen vesicle at the tip of a sporangiophore as sporangiola or within merosporangia (figure 3 ). Zygospores are absent in most clinical isolates. Therefore identification is based primarily on 


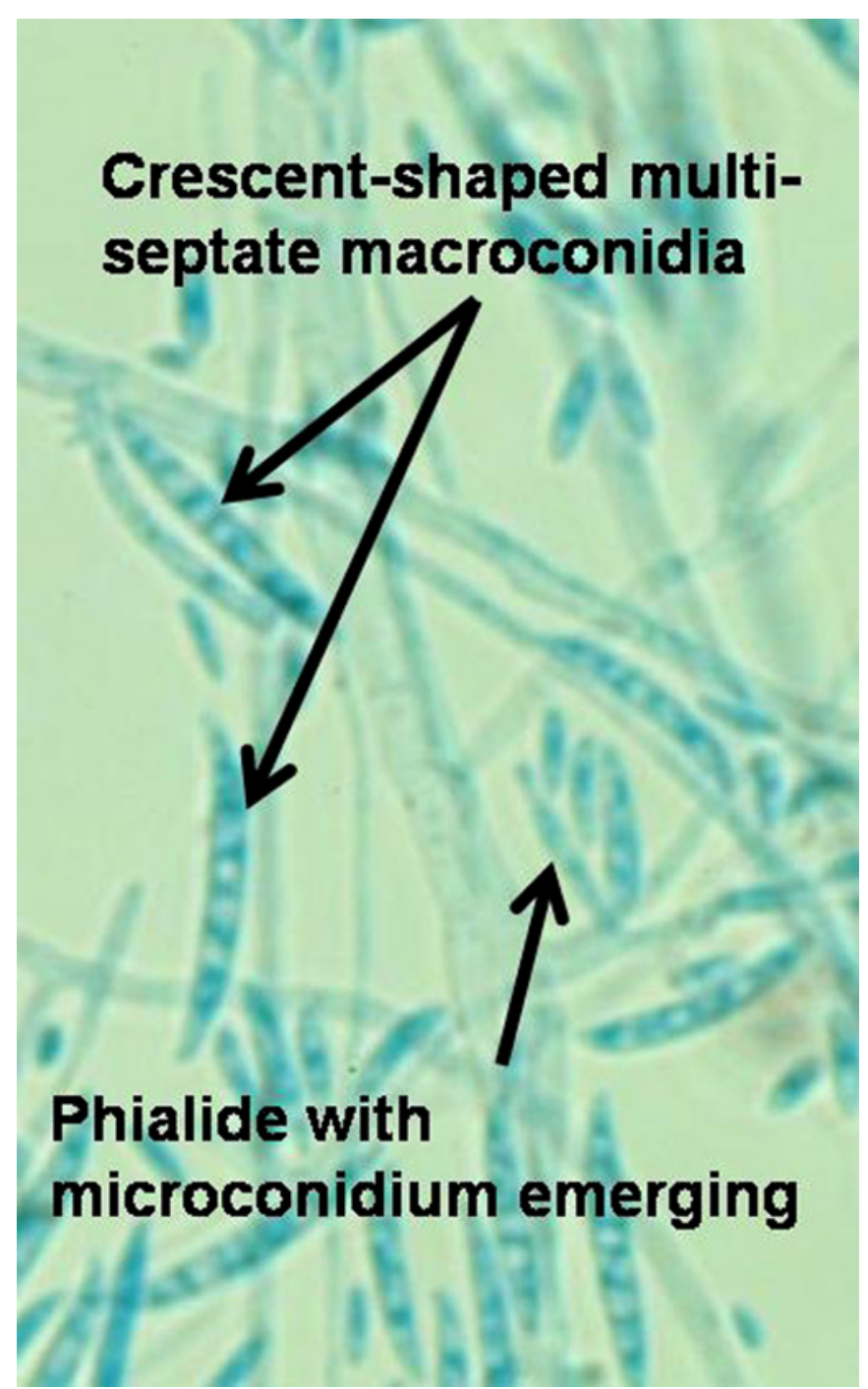

Figure 2 Fusarium microconidia and macroconidia.

sporangial morphology. The shape, colour and surface ornamentation of sporangiospores, the presence or absence of columella (the sterile central axis of the sporangium) and apophysis (a swelling at the apex of the sporangiophores), as well as the arrangement of the sporangiophores and the presence or absence of rhizoids (short branching root-like hyphae) and stolons (running hyphae from which rhizoids and sporangiophores arise) are the most valuable characteristics. Growth temperature studies are helpful. Medically important genera are mostly those in the newly described order Mucoromycotina, which includes Rhizopus, Mucor, Rhizomucor, Lichtheimia (previously Absidia), and Cunninghamella. 6566971

\section{SUMMARY}

The identification and classification of fungi relies mainly on morphological criteria rather than on the nutritional or biochemical differences that are of such importance for bacteria. Medically important fungi produce microscopic sporing structures studied by the use of the light microscope. Medical mycology laboratories are most familiar with the asexual reproduction stage. However, sexual structures are the baseline for fungal taxonomy and nomenclature. ${ }^{72}$ During infections, most pathogenic moulds show only hyphal elements or other,

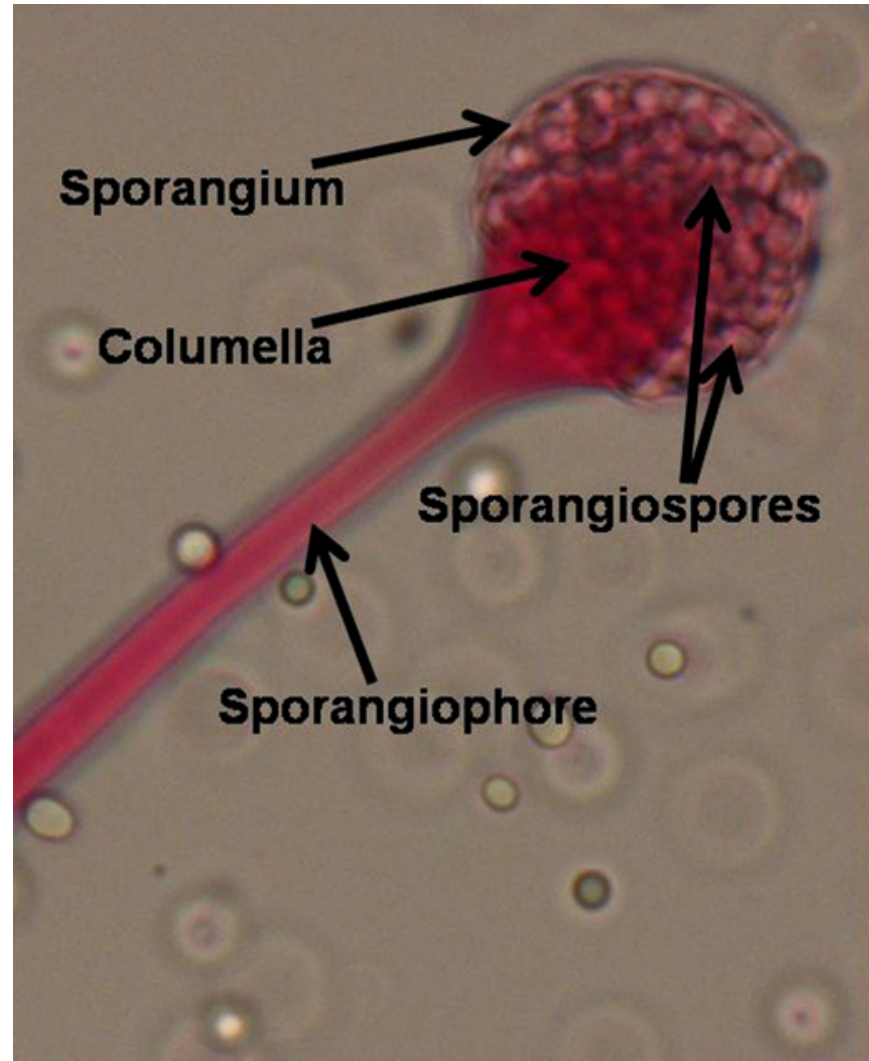

Figure 3 Lichtheimia corymbifera sporing head.

mostly non-specific, structures in host tissue. Although hyphal morphology can provide clues to their identity, cultures are required for accurate identification. Phenotypic identification has been criticised for lack of standardisation, unstable terminology and characteristics, dependence on environmental conditions and a high degree of subjectivity. Another problem is that it cannot be used for fungi that do not grow in culture. ${ }^{72}$

For the most important groups of opportunistic pathogenic moulds, such as Aspergillus, Fusarium and the Mucorales, the isolation and phenotypic identification is relatively straightforward. However, culture is often described as slow, causing misconceptions about its value. ${ }^{66}$ Standardised culture regimens, experience with the microscope and essential understanding of the characteristics of the genus allows most of the identifications needed to be performed quite accurately and, importantly, with little expense. For Aspergillus, for example, the morphological method is the only one that up to now includes all of the species of the genus. ${ }^{73}$

What is more important for the clinical microbiology laboratory is to apply fungal species identification practice to a clinical setting and not for pure taxonomic categorisation. ${ }^{74}$ The ability to differentiate species or strains within a species is useful in predicting disease prognosis, tracing nosocomial infections, epidemiological studies such as outbreak investigations, surveillance for emerging new species and determination of the precise incidence of diseases. ${ }^{73} 75$ However, the more important need in clinical management seems to be an appropriate system of procedures providing rapid prediction of significance and drug susceptibility for clinical isolates. ${ }^{73}$

In 2003, the American Society of Microbiology reported that $89 \%$ of laboratories in the USA performing mycological testing used culture-based identification only, 16\% used serology and fewer than $5 \%$ used molecular tests. The predominance of 


\section{Interactive multiple choice questions}

This JCP review article has an accompanying set of multiple choice questions (MCOs). To access the questions, click on BMJ Learning: Take this module on BMJ Learning from the content box at the top right and bottom left of the online article. For more information please go to: http://jcp.bmj.com/education. Please note: The MCOs are hosted on BMJ Learning - the best available learning website for medical professionals from the BMJ Group. If prompted, subscribers must sign into JCP with their journal's username and password. All users must also complete a onetime registration on BMJ Learning and subsequently log in (with a BMJ Learning username and password) on every visit.

traditional methods supports the need for evolution and optimisation of morphological procedures and methodologies. On the other hand, complete reliance on molecular methods alone can also be misleading, ${ }^{75}$ and it is still difficult to determine which are of practical value in the clinical laboratory. Most have not been sufficiently validated. However, it is likely that molecular testing for selected fungi will be fully incorporated in future diagnostic laboratory practice, and single or multi-locus sequencing will allow the identification of a variety of clinically important fungi and help to determine a common source in an outbreak situation. ${ }^{31}{ }^{74}$ Although molecular methods are still not included in accepted diagnostic criteria, they are widely used for the identification of isolates and there are now international efforts to achieve consensus methodologies for mould identification. $^{74}$

There is a need for standardisation of the procedures, protocols and guidelines among mycology laboratories. There are still gaps in our understanding of the optimal procedures for phenotypic processing, and research in these areas should be encouraged. Also, a renewed effort to train medical and scientific personnel should be made, with emphasis on accurate identification, direct examination, appropriate use of media, clinical relevance and cost effectiveness. These skills and practices must not be abandoned and lost. The correct use of the appropriate method, according to the specific clinical case, diagnostic and therapeutic need, will greatly enhance patient care.

\section{Competing interest None declared.}

Contributors T-AV and CK initiated the paper, undertook the literature searches, extracted the data and wrote the draft manuscript. EJ provided suggestions, added specific parts to the manuscript and provided relevant data for these, contributed to the revisions of the paper and provided the photos. All authors approved the final version.

Provenance and peer review Not commissioned; externally peer reviewed.

\section{REFERENCES}

1. Rees JR, Pinner RW, Hajjeh RA, et al. The epidemiological features of invasive mycotic infections in the San Francisco Bay area, 1992-1993: results of populationbased laboratory active surveillance. Clin Infect Dis 1998;27:1138-47.

2. Perfect JR, Cox GM, Lee JY, et al; Mycoses Study Group. The impact of culture isolation of Aspergillus species: a hospital-based survey of aspergillosis. Clin Infect Dis 2001;33:1824-33.

3. Balajee SA, Sigler L, Brandt ME. DNA and the classical way: identification of medically important molds in the 21st century. Med Mycol 2007:45:475-90.

4. Zhang N, O'Donnell K, Sutton DA, et al. Members of the Fusarium solani species complex that cause infections in both humans and plants are common in the environment. J Clin Microbiol 2006;44:2186-90.

5. Balajee SA, Gribskov JL, Hanley E, et al. Aspergillus lentulus sp. nov., a new sibling species of A. fumigatus. Eukaryot Cell 2005;4:625-32.
6. de Hoog GS, Guarro J, Gene J, et al. Atlas of Clinical Fungi. 2nd edn. Centraalbureau voor Schimmelcultures/Universitat Rovira i Virgili, 2000.

7. Evans EGV, Richardson MD. Medical Mycology: A Practical Approach. Oxford, England: IRL Press, 1989.

8. Richardson MD, Warnock DW. Fungal Infection. Diagnosis and Management. 3rd edn. Massachusetts, USA: Blackwell Publishing, Inc., 2003.

9. Doctor Fungus, Lab Procedures: Collection and Transport of Specimens. 2007. http:// www.doctorfungus.org/thelabor/sec6.pdf

10. Sutton DA. Specimen collection, transport and processing: mycology. In: Murray PR, ed. Manual of Clinical Microbiology. 9th edn. Washington DC: American Society for microbiology, 2007:1728-36.

11. Horvath JA, Dummer $\mathrm{S}$. The use of respiratory-tract cultures in the diagnosis of invasive pulmonary aspergillosis. Am J Med 1996;100:171-8.

12. Yu VL, Muder RR, Poorsattar A. Significance of isolation of Aspergillus from the respiratory tract in diagnosis of invasive pulmonary aspergillosis. Results from a three-year prospective study. Am J Med 1986;81:249-54.

13. Meyer RD, Young LS, Armstrong D, et al. Aspergillosis complicating neoplastic disease. Am J Med 1973;54:6-15.

14. Fisher BD, Armstrong D, Yu B, et al. Invasive aspergillosis. Progress in early diagnosis and treatment. Am J Med 1981;71:571-7.

15. Bennett JE. Aspergillus species. In: Mandell G, Douglas RG, Bennett JE, eds. Principles and Practice of Infectious Diseases. New York, USA: J Wiley, 1979:2005

16. http://www.hse.gov.uk/pubns/misc208.pdf

17. Doctor Fungus, Lab Procedures: Processing and Culturing of Specimens. 2007. http:// www.doctorfungus.com/thelabor/sec8.pdf

18. Moore GS, Jaciow DM. Mycology for the Clinical Laboratory. Reston, Virginia, USA Reston Publishing Company, Inc., 1979.

19. Gupta AK, Gupta AK. Postgraduate institute management protocol for invasive Aspergillus flavus sinusitis: is it effective? Int J Infect Dis 2009;13:134-9.

20. Chander J, Chakrabarti A, Sharma A, et al. Evaluation of Calcofluor staining in the diagnosis of fungal corneal ulcer. Mycoses 1993;36:243-5.

21. Bakare N, Rickerts V, Bargon J, et al. Prevalence of Aspergillus fumigatus and othe fungal species in the sputum of adult patients with cystic fibrosis. Mycoses 2003:46:19-23.

22. Ruchel R, Schaffrinski M. Versatile fluorescent staining of fungi in clinical specimens by using the optical brightener Blankophor. J Clin Microbiol 1999;37:2694-6.

23. Monod M, Baudraz-Rosselet F, Ramelet A, et al. Direct mycological examination in dermatology: a comparison of different methods. Dermatologica 1989;179:183-6.

24. Andreas S, Heindl S, Wattky C, et al. Diagnosis of pulmonary aspergillosis using optical brighteners. Eur Respir J 2000;15:407-11.

25. Phaller MA, McGinnis MR. The laboratory and clinical mycology. In: Anaissie EJ, McGinnis MR, Phaller MA, eds. Clinical Mycology. Philadelphia, PA, USA: Churchill Livingstone, 2003

26. Woods GL, Schnadig VJ. Histopathology of fungal infections. In: Anaissie EJ, McGinnis MR, Phaller MA, eds. Clinical Mycology. Philadelphia, PA, USA: Churchill Livingstone, 2003

27. Chandler FW, Watts JC. Pathologic Diagnosis of Fungal Infections. Chicago, USA ASCP Press, 1987.

28. Musial CE, Cockerill FR 3rd, Roberts GD. Fungal infections of the immunocompromised host: clinical and laboratory aspects. Clin Microbiol Rev 1988;1:349-64.

29. Woods GI, Gutierrez Y. Diagnostic Pathology of Infectious Diseases. Philadelphia, USA: Lea \& Febiger, 1993.

30. Doctor Fungus, Histopathology. 2007. http://www.doctorfungus.org/thelabor/ histopat.htm

31. Glenn DR, Goodman NL. Laboratory diagnosis. In: Merz WG, Hay RJ, eds. Topley and Wilson's Microbiology \& Microbial Infections, Medical Mycology. 10th edn London, England: ASM Press, 2005:82-96.

32. Patterson TF. Aspergillosis. In: Dismukes WE, Pappas PG, Sobel JD, eds. Clinical Mycology. New York, USA: Oxford University Press, 2003:221-40.

33. Larone DH. Medically Important Fungi: A Guide to Identification. 2nd edn Washington D.C., USA: ASM Press, 1993.

34. Tarrand JJ, Lichterfeld M, Warraich I, et al. Diagnosis of invasive septate mold infections. A correlation of microbiological culture and histologic or cytologic examination. Am J Clin Pathol 2003;119:854-8.

35. Revankar SG. Dematiaceous fungi. Mycoses 2007;50:91-101.

36. Milne LJR. Direct microscopy. In: Evans EGV, Richardson MD, eds. Medical Mycology. A Practical Approach. Oxford England: IRL Press, 1989:17-45.

37. Brandt ME, Warnock DW. Laboratory aspects of medical mycology. In: Dismukes WE, Pappas PG, Sobel JD, eds. Clinical Mycology. New York, USA: Oxford University Press, 2003:3-22.

38. Powers CN. Diagnosis of infectious diseases: a cytopathologist's perspective. Clin Microbiol Rev 1998;11:341-65.

39. Sangoi AR, Rogers WM, Longacre TA, et al. Challenges and pitfalls of morphologic identification of fungal infections in histologic and cytologic specimens: a ten-year retrospective review at a single institution. Am J Clin Pathol 2009;131:364-75.

40. De Pauw B, Walsh TJ, Donelly JP, et al. Revise definitions of invasive fungal disease from the European Organization for research and treatment of Cancer/Invasive fungal infections Cooperative group and the National institute of Allergy and infections diseases mycoses study group. Clin Infect Dis 2008;46:1813-21.

41. Ascioglou S, Rex JH, de Pauw B, et al. Defining opportunistic invasive fungal infections in immunocompromised patients with cancer and hematopoietic stem cell transplants: an international consensus. Clin Infect Dis 2002;34:7-14. 
42. Torres HA, Kontoyiannis DP. Hyalohyphomycoses (other than aspergillosis and penicilliosis). In: Dismukes WE, Pappas PG, Sobel JD, eds. Clinical Mycology. New York, USA: Oxford University Press, 2003:252-70.

43. Walsh TJ, Groll AH. Emerging fungal pathogens: evolving challenges to immunocompromised patients for the twenty-first century. Transpl Infect Dis 1999;1:247-61.

44. Anaissie EJ, Bodey GP, Rinaldi MG. Emerging fungal pathogens. Eur J Clin Microbiol Infect Dis 1989;8:323-30.

45. Francis $\mathbf{P}$, Walsh TJ. Approaches to management of fungal infections in cancer patients. Oncology (Williston Park) 1992;6:133-44.

46. Paterson PJ, Seaton S, McLaughlin J, et al. Development of molecular methods for the identification of aspergillus and emerging moulds in paraffin wax embedded tissue sections. Mol Pathol 2003;56:368-70.

47. Paterson PJ, Seaton S, McHugh TD, et al. Validation and clinical application of molecular methods for the identification of moulds in tissue. Clin Infect Dis 2006; 42:51-6.

48. Beuchat LR. Media for detecting and enumerating yeasts and moulds. Int J Food Microbiol 1992;17:145-58.

49. Beuchat LR. Selective media for detecting and enumerating food borne yeasts. Int $J$ Food Microbiol 1993;19:1-14.

50. Fleet G. Spoilage yeasts. Crit Rev Biotechnol 1992;12:1-44

51. Koneman EW, Roberts GD, Wright SE. Prcatical Laboratory Mycology. 2nd edn. Baltimore, USA: Williams \& Wilkins, 1978.

52. Sutton DA, Fothergill AW, Rinaldi MG. Guide to Clinically Significant Fungi. Baltimore, USA: Williams \& Wilkins, 1998.

53. Kontoyiannis DP, Sumoza D, Tarrand J, et al. Significance of aspergillemia in patients with cancer: a 10-year study. Clin Infect Dis 2000;31:188-9.

54. Lionakis MS, Bodey GP, Tarrand JJ, et al. The significance of blood cultures positive for emerging saprophytic moulds in cancer patients. Clin Microbiol Infect 2004;10:922-5.

55. Bille J, Roberts GD, Washington JA 2nd. Retrospective comparison of three blood culture media for the recovery of yeasts from clinical specimens. Eur J Clin Microbiol 1983;2:22-5.

56. Ellis DH. Clinical Mycology. The Human Opportunistic Mycoses. Underdale, Australia: Phizer Inc., Gillingham Printers Pty Ltd, 1994.

57. Tarrand JJ, Guillot $C$, Wenglar $M$, et al. Clinical comparison of the resin-containing BACTEC 26 plus and the isolator 10 blood culturing systems. J Clin Microbiol 1991;29:2245-9.

58. Yeghen T, Kibbler CC, Prentice HG, et al. Management of invasive pulmonary aspergillosis in hematology patients: a review of 87 consecutive cases at a single institution. Clin Infect Dis 2000;31:859-68.
59. Chang YC, Tsai HT, Karos M, et al. THTA, a thermotolerance gene of Aspergillus fumigatus. Fungal Genet Biol 2004;41:888-96

60. Samson RA. The genus Aspergillus with special regard to the Aspergillus Fumigatus Group. In: Brakhage AA, Bernhard J, Schmidt A, eds. Aspergillus fumigatus. Contrib Microbiol. Vol. 2. Basel: Karger, 1999:5-20.

61. Tarrand JJ, Kontoyiannis D, Han X. Culture incubation conditions affect the growth of Aspergillus Spp. in an in vitro model system of tissue phase fungal growth. 42nd ICAAC Abstracts, San Diego, California, September 27-30, 2002. Washington, DC: ASM Press, 2002. M-909.

62. Morris AJ, Byrne TC, Madden JF, et al. Duration of incubation of fungal cultures. J Clin Microbiol 1996;34:1583-5.

63. Verweij PE, Meis JF. Microbiological diagnosis of invasive fungal infections in transplant recipients. Transpl Infect Dis 2000;2:80-7.

64. Campbell CK, Johnson EM, Philpot CM, et al. Identification of Pathogenic Fungi. London, England: Public health laboratory Service, 1996.

65. Johnson EA. An improved slide culture technique for the study and identification of pathogenic fungi. J Bacteriol 1946;51:689-94.

66. McClenny N. Laboratory detection and identification of Aspergillus species by microscopic observation and culture: the traditional approach. Med Mycol 2005;43 (Suppl 1):S125-8.

67. Raper BK, Fennell DI. The Genus Aspergillus. Baltimore MD, USA: the Williams and Wilkins Company, 1965.

68. Klich MA. Identification of Common Aspergillus Species. Utrecht, the Netherlands: Centraalbureau voor Schimmelcultures, 2002.

69. Mycology Online. Identification of Medically Important Fungi. Australia: The University of Adelaide, 2008. http://www.mycology.adelaide.edu.au/ Fungal Descriptions

70. Leslie JF, Summerell BA, Bullock S. The Fusarium Laboratory Mānual. Ames, lowa USA: Wiley-Blackwell, 2006.

71. Hibbett DS, Binder M, Bischoff JF, et al. A higher-level phylogenetic classification of the Fungi. Mycol Res 2007;111:509-47.

72. Guarro J, Gene J, Stchigel AM. Developments in fungal taxonomy. Clin Microbio Rev 1999;12:454-500.

73. Klich MA. Identification of clinically relevant aspergilli. Med Mycol 2006;44 S127-31.

74. Balajee SA, Borman AM, Brandt ME, et al. Sequence-based identification of Aspergillus, fusarium, and mucorales species in the clinical mycology laboratory: where are we and where should we go from here? J Clin Microbiol 2009:47:877-84

75. Balajee SA, Marr KA. Phenotypic and genotypic identification of human pathogenic aspergilli. Future Microbiol 2006;1:435-45. 